\section{Preventing ARDS - another use for ketoconazole}

Aside from its established use as an antifungal agent and its role in the management of advanced prostate cancer, ketoconazole can also prevent the development of adult respiratory distress syndrome (ARDS) and improve survival rates in patients with severe sepsis.

\section{New finding}

These latter effects were shown in a double-blind study by Dr Mihae Yu and Grace Tomasa from Hawaii, US. ${ }^{1}$ The effect on improved survival rates has not been reported before.

In the study, patients with sepsis received ketoconazole $200(n=2)$ or $400(24) \mathrm{mg} / \mathrm{day}$ or placebo (28) orally or via a nasogastric tube, within 24 hours admission to a surgical intensive care unit (ICU). They were treated for a maximum of 21 days.

Development of ARDS and mortality rates in patients with sepsis

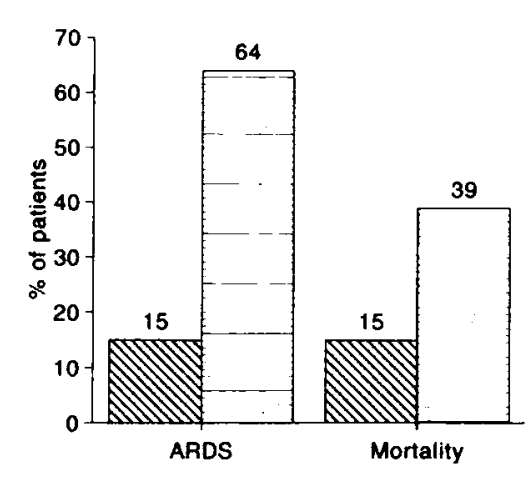

N Ketoconazole $\square$ Placebo imidazole antifungal miconazole, which can be given intravenously, may also be warranted.

1. Yu M, et al. A double-blind, prospective, randomized trial of ketoconazole, a thromboxane synthetase inhibitor, in the prophylaxis of the adult respiratory distress syndrome. Critical Care Medicine 21: 1635-1642, Nov 1993 2. Slotman GJ. Ketoconazole: maybe it isn't the magic potion, but... Critical Care Medicine 21: 1642-1644. Nov 1993
The frequency of ARDS and the mortality rate were significantly lower in ketoconazole compared with placebo recipients [see graph]. However, most deaths were still secondary to multi-organ failure. The number of days on a ventilator and in the ICU, as well as hospital charges, were less in the ketoconazole than in the placebo group; however, these differences were not significant. No serious adverse effects associated with ketoconazole were reported.

\section{Absorption may be a problem}

The findings regarding prevention of ARDS confirm those of a previous study in critically ill surgical patients by Dr Gus Slotman and colleagues also from the US. In an editorial accompanying the study by Yu and Tomasa, Dr Slotman comments that there may be a dose-response relationship for ketoconazole as the patients in his study received 200 $\mathrm{mg} / \mathrm{day}{ }^{2}$ In addition, in the study by Yu and Tomasa, ketoconazole recipients who did not develop ARDS had significantly higher ketoconazole blood levels than those who did; thus, drug absorption may have been hindered in sicker patients.

$\mathrm{Yu}$ and Tomasa conclude that 'ketoconazole might be a viable alternative to using [NSAIDs] in the ICU population, where side effects of bleeding and renal dysfunction, associated with [NSAIDs], are of concern'. They add that studies with another 